Divna D. Glumac

УДК 811.521'367:811.163.41'367

Univerzitet u Beogradu

ДОИ https://doi.org/10.18485/analiff.2017.29.2.6

Filološki fakultet

\title{
ZNAČENJA KAUZATIVA U JAPANSKOM JEZIKU I NEKI PROBLEMI U PREVOĐENJU NA SRPSKI
}

\begin{abstract}
Kauzativna rečenica $\mathrm{u}$ japanskom jeziku, $\mathrm{u}$ kontrastivnom poređenju sa srpskim pokazuje izrazite specifičnosti. U japanskom jeziku kauzativnost se formalizuje na morfološkom nivou, dok se u srpskom jeziku formalizuje na leksičkom i na sintaksičkom nivou. Ključna razlika između dva jezika je što se u japanskom jeziku jednim složenim glagolskim oblikom iskazuju i kauzirajuća i kauzirana radnja, iako ova prva samo kao uopšten, nikako konkretan oblik podsticaja, dok se u srpskom jeziku priroda podstreka iskazuje konkretnim kauzativnim glagolom. Osim toga, japanska kauzativna rečenica izražava i ona značenja i odnose koja nisu obuhvaćena pojmom kauzativnosti u srpskom jeziku. Cilj ovog rada je da se, analizom prevodnih ekvivalenata, otkriju sistemski odnosi koji omogućuju uspostavljanje ekvivalentnosti u prevodu japanske kauzativne rečenice na srpski i pored razlika. Korpus čine dela savremene japanske književnosti na japanskom jeziku nastala u periodu od početka XX veka do danas i njihovi književni prevodi na srpski jezik.
\end{abstract}

Ključne reči: kauzativ, kauzativni glagoli, kauzator, kauzirani, agentivnost, modalnost, implikativnost, rečenična perspektiva, uzrok.

\section{Pojam, tvorba i sintaksičko-semantičke odlike}

Kauzativ se u japanskom jeziku proučava u okviru kategorije glagolskog roda. U dosadašnjim naučnim istraživanjima japanskih lingvista pojmom glagolskog roda obuhvataju se aktiv, pasiv, kauzativ, spontani glagolski rod i potencijal. Ovom kategorijom obuhvaćeni su i prelazni i neprelazni glagoli, a od sedamdesetih godina XX veka u okviru nje proučavaju se i reciprok i refleksiv. Autori kao što su Teramura (1982), Saeki (1984), Nita (1991), Muraki (1991), Kudou (1999) i dr. u ovu kategoriju ubrajaju i glagole odnosne opozicije, deziderativ, rečenice s glagolima davanja i primanja, kao i poseban tip rečenice koja izražava značenje stanja, tzv. konstrukcija ,te aru“. 
U većini tipologija glagolskog roda $\mathrm{u}$ japanskom jeziku pasiv i kauzativ zauzimaju centralno mesto. Dok pasiv za nosioca situacije uzima onog koji radnju prima, odnosno prema kome je radnja usmerena, kauzativ sagledava radnju iz suprotnog pravca, uzimajući za nosioca situacije „treće“ lice, dakle onog koji nije neposredno u vezi sa radnjom ali je nekim svojim činom inicirao ili prouzrokovao njeno vršenje. U oba slučaja agens se pomera sa mesta nosioca rečenice i dobija ulogu dopune. Glavna komunikativna odlika kauzativne rečenice jeste tematizacija kauzatora.

Kauzativ u japanskom jeziku deli se na leksički i afiksalni. U leksički kauzativ Šibatani (Shibatani 1973) ubraja prelazne glagole koji grade prelazno-neprelazne parove glagola nastale iz istog korena, kao tomeru (zaustaviti) - tomaru (zaustaviti se). Šigemori Bučar (Shigemori Bučar 2006) daje drugačiju definiciju leksičkog kauzativa, ubrajajući tu one leksičke jedinice koje nemaju morfološke sličnosti sa osnovnim, upravnim glagolom, ali u odnosu na njega nose značenje kauzativnosti, kao shinu (umreti) - korosu (ubiti). Afiksalni ili morfološki kauzativ nastaje dodavanjem pomoćnog glagola saseru na osnovu aktivnog oblika glagola. Ovako deriviran kauzativ smatra se prototipičnim.

U japanskom jeziku kauzativ se morfološki i semantički izvodi iz aktiva, dodavanjem pomoćnog glagola (sa)seru na osnovu glavnog glagola, čime se povećava valenca glagola za jedan. Pomoćni glagol saseru dodaje se u vidu afiksa na osnovu prelaznih i neprelaznih glagola (V), gradeći sledeću strukturu: „N1-wa N2-wo/ni (N3-wo) V-saseru“. Takva površinska struktura identična je strukturi sa prelaznim monotranzitivnim odnosno ditranzitivnim glagolom. Rečenice imaju identičnu sintaksičku strukturu, ali se razlikuju po semantičkim ulogama njihovih argumenata.

$\mathrm{Na}$ dubinskoj strukturi, međutim, kauzativna rečenica je složena. Strukturu kauzativne rečenice posmatramo kao strukturu sa umetnutom ili uklopljenom rečenicom (Shibatani 1973; Lyons 1977; Teramura 1982), koja je objekat apstraktnog glagola saseru (izazvati). U osnovnu rečenicu „N1-wa...saseru“ uklopljena je rečenica „N2-wa V“ čime se dobija površinska struktura „N1-wa (N2-wa V)-saseru“, „N1 izaziva (N2 čini)“. Tako kauzativna rečenica integriše u jednopredikatsku strukturu dve propozicije, „N1-wa...saseru“ i ,N2-wa V“, od kojih prva predstavlja kauzirajuću a druga kauziranu situaciju. Nosioci dveju korelativnih situacija obično su lica. 
ZNAČENJA KAUZATIVA U JAPANSKOM JEZIKU I NEKI PROBLEMI U PREVOĐENJU...

Kauzativna rečenica svojom jednoobraznom strukturom izražava raznovrsna značenja. Tipična je dvoagentivna rečenica. Imenica na mestu subjekta (N1) izražava kauzatora u službi nosioca kauzativne situacije, dok imenica u ulozi direktnog ili indirektnog objekta (N2) izražava kauziranog, kao onog koji prima dejstvo kauzatora i ujedno je nosilac kauzirane situacije, tj. vršilac radnje glagola u osnovi. Tako su u kauzativnoj rečenici prisutni vršilac i jedne i druge radnje. Kauzator kao vršilac radnje pomoćnog glagola saseru dobija ulogu subjekta, dok kauzirani kao vršilac radnje glavnog glagola dobija ulogu dopune. Kada rečenicu gradi prelazni glagol, kauzirani je označen padeškom pomoćnom rečcom $n i$ za indirektni objekat, dok je direktni objekat prelaznog glagola iskazan imenicom u obliku akuzativa (N3-wo). Kada rečenicu gradi neprelazni glagol, kauzirani može biti označen i padeškom pomoćnom rečcom wo za direktni objekat, a rečenica ima jedan argument manje: „N1-wa N2-wo V-saseru“. Kada je kauzirani označen pomoćnom rečcom za direktni objekat wo, iako živo biće, on gubi agentivnost i svojim svojstvima približava se predmetu radnje. Takva rečenica izražava prisilu i neuvažavanje volje kauziranog. Šibatani (1973: 335) tvrdi da tzv. ,wo kauzativ“ naglašava agensovu pacijativnost dok ,ni kauzativ“ naglašava njegovu agentivnost.

Uvođenjem trećeg lica koje nije direktni učesnik događaja ali zauzima poziciju subjekta, i proterivanjem agensa sa pozicije subjekta na poziciju dopune naizgled je narušena koordinacija između funkcionalne i semantičke strukture rečenice. Ipak, treće lice na poziciji subjekta ima ulogu vršioca radnje upravo zahvaljujući složenoj strukturi predikata, jer svaki od glagola ima svog vršioca sa kojim uspostavlja odnos vršilac-radnja. Tako u osnovi kauzativne rečenice leži dvopropoziciona i heterosubjekatska sintaksička struktura, koja jednim glagolskim oblikom obuhvata dva događaja i dva agensa. To su događaj ,agens kauzativa - kauzativna radnja“ i događaj ,agens-radnja“ (Satou 1986). Vršilac radnje glavnog glagola ima dvojaku ulogu. On je ujedno i primalac dejstva kauzatora (kauzirani) i agens glavnog glagola. Ovakva struktura može se opisati semantičkim modelom koji predlaže Alanović (2011), „X čini $\mathrm{R}_{1}$ tako da $\mathrm{Y}$ čini $\mathrm{R}_{2}$ kao posledicu“, gde kauzator čini radnju saseru tako da kauzirani čini radnju $\mathrm{V}$ kao posledicu. Integrisanjem dve propozicije u kauzativnu rečenicu usložnjavaju se semantičke uloge kauziranog, te on istovremeno deluje i kao objekat kauzirajuće radnje i kao subjekat odnosno agens kauzirane, zadržavajući svoju semantičku ulogu dubinske strukture. 
Pomoćni glagol za iskazivanje kauzativa saseru nosi značenje „N1 čineći nešto izaziva da N2 čini“, pri čemu uopšteno značenje „,čineći nešto", može da predstavlja niz radnji koje se eksplicitno ne specifikuju, a najčešče su to radnje davanja naredbe, zahtevanja, dozvole, zabrane i sl.

\section{Značenja kauzativa}

Suzuki (1972) definiše kauzativni glagol dvojakom prirodom: to je zbir leksičkog značenja glagola aktiva i gramatičkog značenja kauzativa. Prema Suzukiju kauzativni glagoli se koriste u značenju aktivnog prisiljavanja drugoga na radnju, zatim pasivnog davanja dozvole za radnju, ali i u značenju uzroka kada je subjekat kauzativne rečenice neživo.

Kada se početni događaj opiše sa tačke gledišta trećeg lica koje nije učesnik radnje tako što se njemu dodeli glavna uloga, dobija se rečenica koja izražava indirektno dejstvo. Značenja kauzativne rečenice Morita (1973) definiše prema gradaciji u stepenu dejstva i namernog učešća kauzatora u izazivanju radnje drugog lica ili predmeta. Ta gradacija se kreće od direktnog, jednosmernog i aktivnog ka indirektnom i pasivnom dejstvu. Prema Moriti(1973), značenje kauzativa se definiše kao: prelaznost; prisila; izazivanje promene; dozvola, ostavljanje ili puštanje; odgovornost ili osobina; uzročno-posledični odnos. Ovo polazište uticalo je i na druge istraživače, a poslužilo je i kao osnov za podele kauzativa na direktni i indirektni. Ukazivanjem na značenje izazivanja promene stanja, otvorilo se pitanje nevoljnih glagola, što je dalo osnov za nove podele koje uključuju i promenu psihičkih i fizioloških stanja.

Većina istraživača kauzativa u japanskom jeziku, među kojima su Kuroda, Suzuki, Šibatani, Hajacu i dr, slaže se da postoje dva osnovna značenja kauzativa, a to su prisila i dozvola. Značenja prisile i dozvole mogu se dalje razložiti na sledeće: uputstvo; dopuštanje; ostavljanje; nemešanje; činjenje koristi; zabrana; sprečavanje; samoprekor; žaljenje ili kajanje; okrivljavanje drugog i dr. Za semantičku interpretaciju sadržaja kauzativne rečenice u japanskom jeziku značajno je sledeće: odnos između učesnika; njihovo kategorijalno obeležje (živo /土/); postojanje volje agensa da izvrši radnju; uvažavanje volje agensa od strane kauzatora; aktivnost stava kauzatora prema radnji. 
Kauzativnost se u japanskom jeziku ostvaruje u ekstrapersonalnoj, interpersonalnoj i intrapersonalnoj sferi, ali je prototipična kauzativna rečenica u kojoj su učesnici lica. Jedan od relevantnih kriterijuma klasifikacije kauzativa jesu kategorijalna obeležja učesnika kuzativne situacije, od kojih je naročito bitno obeležje živo / \pm /, što se u širem smislu može shvatiti kao agentivnost. Na mestu subjekta kauzativne rečenice može biti živo biće, koje svojim svesnim i voljnim delovanjem pokreće neki drugi entitet na radnju, a može biti i situacija, koja predstavlja uzrok radnje drugog. Utvrđivanjem prisustva obeležja živo uspostavlja se broj agentivnih učesnika, te se na osnovu tipologije učesnika kauzativi dele na dvoagentivne i jednoagentivne. Dvoagentivni su oni gde i nosilac kauzirajuće i nosilac kauzirane situacije deluju kao agensi. Ulogu kauzatora ne može zauzeti biće samo po sebi, već to mora biti neka njegova radnja, stanje ili postignuće. U dvoagentivne kauzative u širem smislu ubrajaju se oni kod kojih je u ulozi kauzatora umesto živog bića njegova akcija, osećanje, odnosno manifestacija osećanja, emocija, kao na primer tuga, ćutanje, obećanje i sl. Na mestu objekta kauzativnih glagola dvoagentivnih rečenica, po pravilu stoje imenice koje označavaju ljude, ređe životinje. Kauzator svesno i namerno deluje na kauziranog, čime ovaj ostvaruje zadati rezultat.

U japanskom jeziku kauzativ je i sociološka i psihološka kategorija. On opisuje odnos između kauzatora i kauziranog, u kojem je kauzator po pravilu nadređeno lice. Kauzativna rečenica ističe ulogu kauzatora kao onog koji je odgovoran za neki događaj u kojem sam nije učestvovao. Ta uloga uslovljena je socijalnim okvirom. To može biti porodični, pedagoški, poslovni i drugi okvir, u kojem je se iskazuje odnos učitelj učenik, roditelj - dete, poslodavac - radnik i sl. Kauzator ne nastupa nužno kao naredbodavac iz lične koristi ili radi demonstracije svoje moći već je njegova naredba u funkciji vaspitanja, izvršenja posla i sl. Kauzativ takođe izražava i subjektivni osećaj odgovornosti kauzatora zbog toga što je izazvao događaj ili osećaj krivice i samoprekora zbog toga što nije sprečio da se događaj realizuje. S obzirom na navedeno, obavezna je i modalna indikacija korelativnih situacija.

Van Valin i Lapola (Van Valin, LaPolla 1997) ukazuju na problem implikativnosti ${ }^{1} \mathrm{u}$ vezi sa kauzativnošću. Implikativni kauzativi su oni u

1 U literaturi se koriste i termini kao što su „rezultativnost“ (Piper 2001) ili „faktivnost“"(Alanović 2012). 
kojima se zahteva da se kao rezultirajuće stanje radnja osnovnog glagola ostvari, dok neimplikativni to ne traže. U japanskom jeziku, kauzativi su isključivo implikativni. ${ }^{2}$ Kauzirani izvršava radnju i ne očekuje se da može da odbije njeno izvršenje, samim tim što je podređen.

Pored značenja aktivnog prisiljavanja drugoga na radnju ili pasivnog davanja dozvole tipičnih za dvoagentivne rečenice, kauzativne rečenice u japanskom iskazuju i specifična značenja, kao što su: uzrok; odgovornost, tuđa ili svoja; delovanje na predmete kojima je svojstveno odnosno nije svojstveno vršenje radnje; odnos deo-celina ili u širem smislu odnos posesije, koji se uspostavlja između konstituenta u ulozi subjekta i onog u ulozi direktnog objekta, o čemu su posebno istražvale Sato (Satou 1990) i Hajacu (Hayatsu1991), i dr. Kauzativom se opisuju i situacije u kojima su oba učesnika živa bića ali ne nastupaju voljno. Tada rečenica ima uzročno značenje i izražava izazivanje emocionalnih stanja ili nevoljnih radnji kauziranog. Podsticajno dejstvo kauzatora može biti voljna radnja ali i neka njegova osobina ili stanje. Kauzativ izražava uzrok i kada je bar jedan od učesnika neživo. Kao i kod rečenice uzroka, i u rečenicama kauzativa posesije kauzator odnosno kauzirani ne moraju nužno biti iskazani imenicama sa obeležjem živo /+/, a radnja kauzatora odnosno kauziranog može da izražava i stanje, a ne samo događaj. Kauzativni glagoli u japanskom jeziku koriste se i kao prelazni onda kada neprelazni glagol nema svoj prelazni parnjak.

\section{Problemi u prevođenju japanskog kauzativa na srpski}

Specifičnost japanske kauzativne rečenice je što oblik podstreka kauzatora nije eksplicitno dat niti je iskazan u vidu zasebne propozicije, već je izražen apstraktno, pomoćnim glagolom saseru, koji se dodaje na osnovu glagola radnje čiji je nosilac kauzirani. Upravo zbog toga što glagol saseru u sebi krije različite konkretne oblike podsticaja, sintaksički jedinstvena struktura „kauzator-ga kauzirani-wo/ni (objekat-wo) glagolsaseru“ omogućava da se izraze različita kauzativna značenja, kao što

2 Ukoliko se želi iskazati neimplikativnost, u japanskom jeziku se to izražava oblikom za voluntativ kauzativnog glagola u konstrukciji ,-saseyou to suru“ (npr. ikaseyou to shimashita, ,hteo sam da ga pošaljem / nateram da ode“). 
su prisila, dozvola, zabrana, puštanje, sprečavanje, ostavljanje na miru, uputstvo, nega ili briga o nemoćnom, prekor, samoprekor, uzrok i dr. Ova specifičnost japanske kauzativne rečenice predstavlja problem u razumevanju i prevođenju na srpski. Osnovna razlika između japanskog i srpskog u pogledu iskazivanja kauzativnosti je u sredstvima formalizacije kauzativa. Za razliku od japanskog jezika, u srpskom jeziku ne postoji morfolološki lik koji gradi kauzativ. Najčešči oblik formalizacije kauzativnog značenja u srpskom je leksički, pomoću kauzativnih glagola - obligativnim, permisivnim i stimulativnim, uz obavezno iskazivanje konkretnog značenja podstreka i vrste kauzativnog odnosa među učesnicima, a radnja kauziranog se iskazuje dopunskom, izričnom rečenicom.

U prevodu dvoagentivne kauzativne rečenice najpre se utvrđuje da li ona izražava značenje dozvole ili prisile. Jedan od pokazatelja može biti padeška pomoćna rečca koja stoji uz ime kauziranog. Izučavajući padešku oznaku kauziranog tj. agensa u kauzativnim rečenicama u raznim jezicima, Komri uspostavlja sledeću hijerarhiju: instrumental > dativ > akuzativ, prema kojoj instrumental kao padež najvišeg ranga ove hijerarhije korespondira sa višim stepenom zastupljenosti svojstva agentivnosti, dok akuzativ kao padež najnižeg ranga odgovara najnižem ili nepostojećem stepenu agentivnosti (vidi u: Van Valin, LaPolla 1997: 587). On tvrdi da u nekim jezicima postoji alternacija u oznaci kauziranog. Ona se u japanskoj kauzativnoj rečenici uočava kod neprelaznih glagola kada je agens živo. Takav agens se može označiti padeškom pomoćnom rečcom za dativ ni ili padeškom pomoćnom rečcom za akuzativ wo.

U literaturi o kauzativu u japanskom jeziku ova alternacija u oznaci agensa objašnjava se time da se upotrebom dativa uzima u obzir volja agensa da izvrši radnju, čime se značenje kauzativne rečenice tumači kao dozvola ili puštanje da agens izvrši radnju prema svojoj volji, dok se upotrebom akuzativa zanemaruje volja agensa, čime se agens izjednačava sa pacijensom ili predmetom radnje, a značenje rečenice se tumači kao prisila (Iori 2002: 126). Takav je sledeći primer:

両親は子どもにアメリカへ留学させました。

Ryoushin-wa kodomo-ni amerika-e ryuugaku sasemashita.

Roditelji su dozvolili detetu da studira u Americi. (jer je ono tako želelo) 
両親は子どもをアメリカへ留学させました。

Ryoushin-wa kodomo-wo amerika-e ryuugaku sasemashita.

Roditelji su poslali dete da studira u Americi. (protiv njegove želje)

Prva rečenica, u kojoj je kauzirani označen rečcom $n i$, tumači se kao kauzativ dozvole i u prevodu je upotrebljen permisivni glagol dozvoliti, čija dopuna u srpskom je imenica u dativu. Druga rečenica, u kojoj je kauzirani označen rečcom wo, izražava kauzativ prisile i u prevodu je upotrebljen prelazni glagol poslati sa imeničkom dopunom u akuzativu, što je čest prevodni ekvivalent kauzativa glagola kretanja. Ovo pravilo, međutim, odnosi se samo na neprelazne glagole. Teramura (1982) ipak smatra da je ovakvo određenje suviše kategorično, tvrdeći da su u izboru između rečci ni i wo presudne leksičke odlike glagola. Prema njemu, agens (kauzirani) se označava rečcom wo kada je u osnovi kauzativa neprelazni glagol koji izražava „trenutnu promenu raspoloženja“, kao što su shitsubou suru (razočarati se) ili gyotto suru (prepasti se), kao i glagoli warau (smejati se) i naku (plakati) (Teramura 1982: 294).

Kod prelaznih glagola distinkcija u oznaci kauziranog rečcom wa ili $n i$ ne postoji jer se kauzirani po pravilu označava samo rečcom $n i$. U takvim slučajevima, prilikom tumačenja značenja rečenice kao prisile ili dozvole može se osloniti na priloške izraze kao što su kanarazu (obavezno), motomete (po svaku cenu), shiite (silom), murini (nasilno), muriyarini (na silu), umu wo iwasezu (ne pitajući ga), iyaounaku (hteo-ne-hteo), doushitemo (po svaku cenu) odnosno jiyuuni (slobodno), omou toori ni (onako kako želi), jishin (sam) - ukoliko su oni eksplicitno iskazani. Takvi su sledeći primeri:

先輩は 私に 無理に 酒を 飲ませた。(Sunagawa 1998, 132)

Senpai-wa watashi-ni murini sake-wo nom-aseta.

Kolege su me na silu naterale da pijem.

とても難しい子だし、傷つきやすい子だし、無理に何かをやらせよう としても無駄だと思いますね。(Murakami 1988b: 135)

Totemo muzukashii kodashi, natsukiyasui kodashi, murini nanikawo yaraseou toshitemo mudadato omoimasune.

Veoma je teško dete, ranjivo, i ako pokušavate da je na silu naterate da bilo šta uradi, neće vam uspeti. (Murakami 2013: 288) 
ZNAČENJA KAUZATIVA U JAPANSKOM JEZIKU I NEKI PROBLEMI U PREVOĐENJU...

父親と 母親は 子どもたちに 自由に 意見を しゃべらせまし た。(Shokyuu nihongo: 135)

Chichioya-to hahaoya-wa kodomotachi-ni jiyuuni iken-wo shaberasemasita.

Otac i majka su dozvolili deci da slobodno izlože svoje mišljenje.

それで㝿の思う通りにさせて、私は手を引きました。(Soseki１965:

Sorede kareno omou toori ni sasete, watashi-ha te-wo hikimashita.

Povukao sam se, puštajući ga da uradi kako želi. (Soseki 2003: 184)

いずれにせよそれはあの子自身に決めさせればいいことでしょうか? (Murakami 1988b: 135)

Iyureni seo sore-wa anoko jishin-ni kimesasereba iikotodeshouka?

U svakom slučaju, zar nije bolje da je pustite da sama o tome odluči? (Murakami 2013: 288)

Problem u prevođenju, međutim, predstavlja to što u japanskoj kauzativnoj rečenici najčešće nema eksplicitnog i utvrđenog signala koji upućuje na značenje prisile, molbe, uputstva, koristi, dozvole, puštanja i dr. Tumačenje značenja kauzativne rečenice oslanja se na razumevanje konteksta, konkretne situacije i događaja koji se opisuju, odnosa između kauziranog i kauzatora i dr. Uzima se u obzir i izvor radnje glavnog glagola. Kada je izvor radnje u volji kauzatora, on naređenjem ili drugim sredstvima deluje na drugo lice da izvrši radnju. Kada je izvor radnje u odluci samog vršioca, ali se ipak upotrebi kauzativna rečenica i situacija se izrazi kao da je radnju uzrokovao neko drugi dozvolom ili zabranom, takva kauzativna rečenica govori da postoji neki socijalni, psihološki ili drugi odnos između vršioca radnje i kauzatora. Prve su rečenice naredbe ili prisile, dok su druge rečenice dozvole, dopuštenja ili „ne-lične namere“ (Satou 1986: 111). Slično, rečenice kauzativa činjenja koristi po svom značenju se graniče sa rečenicama kauzativa dozvole. Zadatak je prevodioca da iz konteksta proceni da li je inicijator radnje kauzator ili kauzirani i da u skladu s tim rečenicu interpretira kao kauzativ činjenja koristi ili kauzativ dozvole.

Jedna od osnovnih intepersonalnih situacija, ,ponuditi nekome da sedne“, opisuje se u japanskom jeziku kauzativnim oblikom neprelaznog glagola suwaru (sesti). Takvi su i sledeći primeri: 
1そこで内供は弟子の一人を膳の向うへ坐らせて、飯を食う 間中、広さ一寸長さ二尺ばかりの板で、鼻を持上げていて貪う事 にした。(Hana)

Zato je za vreme jela jednog od svojih učenika morao posaditi preko puta sebe, kako bi mu ovaj pridržavao nos štapom širokim tri i dugačkim oko šezdeset santimetara. (Akutagava 2002: 5)

2 彼は広々としたリビング・ルームに僕らを通し、大きなソファに座 らせ [...] (Murakami 1988b: 59)

Uveo nas je u prostranu dnevnu sobu, smestio nas je na veliki kauč i iz kuhinje na poslužavniku doneo dva piva i koka-kolu i tri čaše. (Murakami 2013: 246)

3 奥さんは火鉢の前に敷いた座蒲団の上へ私を座らせて $[. .] \quad.($ Soseki 1965: 386)

Učiteljeva supruga mi ponudi da sednem na jastuk kraj mangala. (Soseki 2003: 56)

4彼らは部屋に入るとコートを脱ぎ、‥それから僕をスチール製の事 務椅子に座らせた。(Murakami 1988a, 278)

Kad su ušli [inspektori], skinuli su mantile, presavili ih i stavili na pomoćnu stolicu, a meni su ponudili da sednem na čeličnu kancelarijsku stolicu. (Murakami 2013: 171)

5 そして細い指を寺に上げて向かいの椅子に座らせた。(Murakami 1988b: 234)

Podigla je tạnak prșt i pokazala mi da sednem na stolicu naspram nje. (Murakami 2013: 346)

U svim rečenicama kauzirani je iskazan imenicom uz pomoćnu rečcu za objekat wo. Kauzativ glagola suwaraseru, međutim, ne izražava uvek prisilu. U prevodu se realizuje na različite načine, u zavisnosti od odnosa između učesnika situacije i od nivoa učtivosti u ophođenju. Glagol sedeti u srpskom jeziku ima svoj prelazni parnjak posaditi uz semantičko ograničenje da je lice u ulozi objekta glagola (kauzirani) podređeni u odnosu na vršioca radnje (kauzatora). U ulozi kauziranog najčešće su imenice sa značenjem ,dete“, „učenik“ i sl., kao što je to i u primeru 1.

U primeru 2 opisuje se odnos domaćin-gost, a glagol je preveden prelaznim situitivnim glagolom smestiti sa kauziranim u ulozi direktnog 
objekta. Situacija govori o manje formalnim odnosima između kauzatora i kauziranog. Kada situacija izražava viši nivo učtivosti, kao što je u primeru 3, u prevodu je upotrebljen stimulatvni glagol ponuditi uz glagol sedeti kao predikat dopunske rečenice.

Ovakve rečenice predstavljaju problem za prevođenje jer se samo na osnovu poznavanja šireg konteksta i odnosa među učesnicima može zaključiti da li je značenje kauzativa učtiva ponuda ili prisila nižeg ili višeg intenziteta. Značenja kauzativa apstrahovana u pomoćnom glagolu saseru moraju se konkretizovati u srpskom jeziku. Tumačenje značenja i intenzitet prisile u japanskom ogledaju se u izboru glagola u srpskom. Još veći problem predstavlja primer 4 , gde se situacija može tumačiti na različite načine. U ulozi kauzatora su policijski inspektori, koji jesu nadređeni time što predstavljaju autoritet. Kauzirani, govornik, jeste podređeni pred autoritetom institucije u kojoj se nalazi, ali je istovremeno i ugledni građanin, učitelj, koji je igrom prilika priveden kao osumnjičeni na ispitivanje. Ovakvo poznavanje šireg konteksta, donosi različita tumačenja značenja kauzativa, što uslovljava i izbor glagola u srpskom. Prelazni parnjak glagola sedeti u srpskom jeziku, posaditi, pokazuje se neadekvatnim zbog gorenavedenog semantičkog ograničenja, a odnos podređeni-nadređeni ovde se relativizuje. Ukoliko se kauzirani interpretira kao predmet radnje čija je volja zanemarena, uz glagol posaditi moguća je i prevodna varijanta „stavili su me da sednem“. Ukoliko se kauzirani ipak uvaži kao osoba od ugleda, uz prevod ,ponudili su mi da sednem“, moguća je i varijanta „smestili su me da sednem“. Upotreba glagola dati u izrazu ,dali su mi da sednem“ tumačila bi se kao dozvola, ali i izvesna doza prisile ne bi bila nužno isključena.

U primeru 5 intenzitet prisile je slab. Kauzator izaziva radnju drugog lica fizičkim pokretom. Takva kauzirajuća radnja je i eksplicitno iskazana zavisnom klauzom glagolom u vezivnom obliku (glagol + te) yubiwo agete (podigla je prste). U prevodu kauzativnog glagola suwaraseru izražen je fizički stimulans (,,pokazala mi da sednem“).

Drugi problem u vezi sa prevođenjem je problem implikativnosti. Dok su u japanskom kauzativi isključivo implikativni, u srpskom jeziku implikativnost nije uvek nužna. Glagoli sa kauzativnim značenjem u srpskom dele se na implikativne (naterati, prisiliti, primorati), negativno implikativne (sprečiti) i neimplikativne (zapovediti, narediti, zabraniti, 
dozvoliti, nagovoriti, zahtevati) (Batistić 1978: 78). Uzimajući u obzir i vidska obeležja glagola, u neimplikativne se svrstavaju još imperfektivni parovi navedentih trenutnih glagola (zapovediti - zapovedati i dr.) kao i imperfektivni parovi implikativnih glagola (terati i dr.). Samo implikativni i negativno implikativni glagoli u prošlom vremenu impliciraju izvršenost radnje dopunske rečenice, dok je kod neimplikativnih glagola nejasno da li se ta radnja izvršila ili nije (Batistić 1978: 78).

U vezi s problemom implikativnosti je i promena rečenične perspektive u prevodu. S obzirom da japanska kauzativna rečenica opisuje dvoagentivnu situaciju u kojoj su i kauzirajuća i kauzirana radnja izvršene, u prevodu je moguće situaciju iskazati i iz perspektive kauzatora i iz perspektive kauziranog. Kada se bira kauzatorova tačka gledišta, najčešće se prevodi kauzativnim glagolima prinude kao što su primorati, tražiti, narediti, terati i dr. u perifrastičnoj konstrukciji sa izričnom rečenicom čiji glagol izražava radnju kauziranog. Kada se kauzirani tretira kao predmet radnje time što se u potpunosti zanemaruje njegova volja, kauzativ se u srpskom realizuje prelaznim glagolom kao što je u slučaju glagola sesti glagol posaditi. Kauzativnost se može i kontekstualno realizovati upotrebom glagola reći kada se govori slabijoj prisili. Slično je i sa glagolom pozvati. Glagol dati može da znači i prisilu kada je kontekstualni okvir takav da se odnosi na zaduženje ili posao koji se nameće kauziranom. Kada se u prevodu događaj opiše iz perspektive kauzatora, i to nekim od neimplikativnih glagola, ostaje nejasno da li je kauzirani zaista i izvršio radnju koju mu je kauzator zadao, naredio, dodelio, ponudio i sl. O značenju implikativnosti radnje zaključuje se na osnovu toga što je kauzator autoritet. U prevodu rečenice kauzativa uputstva značenje implikativnosti slabi. To je tipično za rečenice u kojima je kauzativni glagol u ne-prošlom (sadašnje-budućem) vremenu i izražava radnju koja je deo budućeg plana ili se još nije ostvarila, kao i kod rečenica u kojima je kauzator podređeni. Situacije kada je kauzator podređeni su ređe, a tada rečenica izražava molbu, nagovaranje i slične oblike voljnog podsticaja kao spoljašnjeg uzroka nižeg intenziteta. Takva je sledeća rečenica:

Kが新しく引き移った時も、私が主張して彼を私と同じように取り扱 わせる事に極めました。(Soseki 1965: 482)

Kada se K. doselio, tražio sam da se prema njemu postupa na isti način kao sa mnom. (Soseki 2003: 195) 
U datoj rečenici kauzator-govornik nema moć da naredi ili natera kauziranog da izvrši radnju. On može samo oštrije da izrazi svoju želju, zahtev ili molbu, ali krajnju odluku o tome da li će izvršiti radnju donosi kauzirani. Kauzativnost se ovde može izraziti glagolima kao što su tražiti, insistirati ili zahtevati. Još slabiji intenzitet prisile i veću zavisnost od volje kauziranog izražava sledeća rečenica, gde je kauzativnost u prevodu iskazana glagolom nagovarati u nesvršenom vidu.

内心では勿論弟子の僧が、自分を説伏せ て、この法を試みさせるの を待っていたのである。(Hana)

Naravno, u dubini duše je jedva čekao da učenik počne da ga nagovara da isproba metod. Mora da je i učeniku bila jasna Naiguova namera. (Akutagava 2002: 8)

Kao opšte pravilo, perspektiva se u prevodu menja kada je naglašeno značenje modalnosti i kada treba naglasiti implikativnost radnje. Značenje modalnosti naročito je istaknuto kod kauzativa prisile ili zabrane. Opet, iskazana iz ugla kauziranog, rečenica potvrđuje implikativnost radnje, ali često izostane značenje kauzativnosti. Ukoliko se kauzativ u srpskom jeziku izražava gramatički, to se najčešće čini uzročnom rečenicom ili predloškopadežnim adverbijalima sa uzročnim značenjem (Piper 2005). Najčešći oblici za iskazivanje kauzirajuće situacije sa značenjem spoljašnjeg uzroka su genitivne konstrukcije s predlozima s tipično uzročnim značenjem (zbog i usled), konstrukcije s predlozima od i pod, zatim akuzativne konstrukcije s predlogom na (na predlog), participske konstrukcije (ohrabren pristalicama) i glagolski prilozi (zahvaljujući) (Piper 2005: 798). Specifična je i upotreba kauzativa kada se ističe odgovornost ili zasluga kauzatora. Kada se takva rečenica prevede iz perspektive kauziranog, ime kauzatora se najčešće iskazuje predloškopadežnim adverbijalom uz predlog zbog ili dativskom konstrukcijom uz glagolski prilog zahvaljujući, kao u sledećim primerima:

1 其頃わたくし共は北山の掘立小屋同樣の所に寝起をいたして、紙屋 川の橋を渡つて織場へ通つてをりました が、わたくしが暮れてから、食物 などを買つて歸ると、弟は待ち受けてわて、わたくしを一人で稼がせては 濟まないと申してをりました。(Takasebune)

U to vreme smo živeli u jednoj straćari u Kitajami i ja sam na posao odlazio prelazići most na reci Kamija, a kad bih se po pomrčini vraćao kući 
noseći nabavljene namirnice, on bi me iščekivao i stalno mi se izvinjavao što sam zbog njega morao sam da zarađujem. (Ogai 2013: 22)

2 彼女のイタリア語はずいぶん上達していたし、…、もしわたしだけ で旅行していたらまず経験しなかったようなことをいろいろ経験させてく れた。(Murakami 2001: 144)

Njen italijanski je prilično napredovao, a bila je puna zdrave radoznalosti, pa sam zahvaljujući njoj i ja iskusila mnoge stvari koje sigurno ne bih da sam sama putovala. (Murakami 2004: 101)

Kao što pokazuje primer 1, prevod sa tačke gledišta kauziranog omogućava i izražavanje modalnog značenja, konstrukcijom sa modalnim glagolom ,morati da + prezent“.

Rečenična perspektiva se u prevodu menja i kada kauzativni glagol nema prelazni parnjak ili kada je nemoguće iskazati kauzirajuću radnju. Takav je sledeći primer:

学生運動にかかわってどうこうとか、恋人を妊娠させて捨ててどうこ うというようなかなり月並みな傷だったが、まあ何もないよりはましだっ た。(Murakami 1988a: 66)

Banalne patnje, te nešto u vezi sa studentskim pokretom, te zato što je ostavio devojku koja je sa njim zatrudnela, no bolje išta nego ništa. (Murakami 2013: 109)

$\mathrm{U}$ datoj rečenici neprelazni glagol u osnovi kauzativa ninshin suru (zatrudneti) u srpskom nema prelazni parnjak, te se situacija saopštava iz perspektive kauzranog, dok je kauzator izražen imeničkom frazom u predloškoj konstrukciji, u instrumentalu s predlogom $s a$. Izmenjena perspektiva i postavljanje kauziranog na mesto subjekta u prevodu karakteristično je za kauzativne rečenice koje izražavaju posesiju, kao i za kauzativne rečenice sa neživim kauzatorom čije značenje se tada približava značenju uzročnika, kao što je u sledećem primeru:

\section{その泣き声は彼の周囲へ、一時に父や母を集まらせた。(Shiro)}

$\mathrm{Na}$ taj plač se istog trenutka oko njega okupiše i otac i majka. (Akutagava 2004: 36) 
ZNAČENJA KAUZATIVA U JAPANSKOM JEZIKU I NEKI PROBLEMI U PREVOĐENJU...

Navedeni su samo neki od problema u prevođenju kauzativne konstrukcije. Problemi kao što su vezivanje priloške odredbe ili prevođenje specifičnih tipova kauzativa kao što su rečenice kauzativa posesije zahtevaju posebnu pažnju i prevazilaze obim ovog istraživanja, te ih ovde nećemo obrađivati.

\section{Literatura}

Alanović, M. (2011). Kauzativnost - manipulativnost: od koncepta ka formi. Novi Sad: Filozofski fakultet u Novom Sadu.

Alanović, M. (2012). Kauzativno-manipulativni glagoli: derivaciono motivisane semantičke i argumentne varijacije. Tvorba reči i njeni resursi u slovenskim jezicima: zbornik radova sa četrnaeste međunarodne naučne konferencije Komisije za tvorbu reči pri Međunarodnom komitetu slavista / glavni urednik Rajna Dragićević.

Batistić, T. (1978). O nekim aspektima analize kauzativnih glagola. Južnoslovenski filolog XXXIV. Beograd, 59-86.

Hayatsu, E. (1991). Shoyuusha shugo no shieki ni tsuite. Nihongo gakka nenpou 13. Tokyo: Toukyogaikokugo daigaku, 1-26.

Hayatsu, E. (2004). Shieki hyougen. Asakuranihongo kouza 6: Bumpou II, Ed.Keisuke Onoe, Asakurashoten, 128-150.

Iori i. i dr. (2002). Chuu, joukyuu wo oshieru hito no tame no nihongobumpou handobukku. Tokyo: 3A.

Ivić, M. (1983). Lingvističke konsekvence različitog pristupa odnosu 'deo-celina'. Lingvistički ogledi. Beograd: Prosveta, 215-225.

Kudou, M. (1999). Gendai nihongono tensu, asupekuto, voisu ni tsuite sougouteki kenkyuu. 1998-99 nendo kagakukenkyuu houkoku, Ippankenkyuu (B) kadai, No.63450058, 5-39.

Kuroda, S.Y. (1965). Generative Grammatical Studies in the Japanese Languages, Ph.D. Dissertation. MIT.

Lyons, J. (1977). Semantics, Vol.2. Cambridge University Press.

Muraki, S. (1991). Voisu no kategori to bunkouzou. Voisuteki hyougen to jikoseigyousei, ur. Nitta Yoshio, Kuroshio, 1-30.

Nitta, Y. (1991). Voisuteki hyougen to jikoseigyousei. Nihongo no voisu to tahousei, ur. Nitta Yoshio. Tokyo: Kuroshio, 31-57. 
Piper, P. (2001). Jezik i prostor, 2. Izdanje. Beograd: Čigoja, Biblioteka XX vek.

Piper, P. (2005). Sintaksa savremenog srpskog jezika. Prosta rečenica. Red. Milka Ivić. Beograd: Institut za srpski jezik SANU, Beogradska knjiga; Novi Sad: Matica srpska.

Saeki, T. (1984). Tai ni yoru doushi bunrui ni mukete: jita to shieki soshite judou. Kokugogoishino kenkyuu, 381-399.

Satou, S. (1986). Shiekikouzou no bun. Kotobano kagaku 1. Tokyo: Gengogaku kenkyuukai, 89-179.

Satou, S. (1990). Shiekikouzou no bun (2): gen'in kankei wo hyougen suru baai. Kotobano kagaku 4. Tokyo: Gengogaku kenkyuukai, 103-157.

Shibatani, M. (1973). Semantics of Japanese Causativation. Foundations of Language 9, 327-373.

Shigemori Bučar, C. (2006). Causative Constructions in Japanese and Slovene. Linguistica XLVI. Ljubljana, 191-202.

Shokyuu nihongo (2001). Shokyuu nihongo bunpou kaisetsu. Tokyo Gaikokugo Daigaku Ryugakuse Nihongo Kyoiku Senta. Tokyo: Bonjinsha.

Stevanović, M. (1974). Savremeni srpskohrvatski jezik: II Sintaksa. Beograd: Naučno delo.

Stojanović, S. (1996). Binarne relacije posesije u engleskom i srpskohrvatskom jeziku. Beograd: Filološki fakultet.

Sunagawa, Y. (1998). Kyoushi to gakushuusha no tame no nihongo bunkei jiten. Tokyo: Kuroshio.

Suzuki, S. (1972). Nihongobunpou - keitairon. Kyouiku bunko 3. Tokyo: Mugishobou.

Tanasić, S. (1996). Iskazivanje agensa uz deverbativne imenice. Južnoslovenski filolog LII, 79-87.

Tanasić, S. (2005). Sintaksičke teme. Beograd: Beogradska knjiga.

Teramura, H. (1982). Nihongo no shintakusu to imi I. Tokyo: Kuroshio.

Van Valin, R.D.Jr., R. LaPolla (1997). Syntax: Structure, meaning and function. Cambridge University Press.

Izvori

Akutagava, R. (2002). Nos. Beograd: Rad.

Akutagava, R. (2004). Beli. Sombor: Publikum.

Akutagava, R. (2008). Biseijeva vernost. Sombor: Publikum. 
ZNAČENJA KAUZATIVA U JAPANSKOM JEZIKU I NEKI PROBLEMI U PREVOĐENJU...

Akutagava, R. (2011). Pakao i druge priče. Beograd: Tanesi.

Hana. Akutagawa, R. [On-line]. Dostupno preko: http://www.aozora.gr.jp/ cards/000879/files/42_15228.html [24.07.2014.]

Imogayu. Akutagawa, R. [On-line]. Dostupno preko: http://www.aozora.gr.jp/ cards/000879/files/55_14824.html [28.09.2014.]

Inu to fue. Akutagawa, R. [On-line]. Dostupno preko: http://www.aozora.gr.jp/ cards/000879/files/56_15161.html [28.09.2017.]

Jigokuhen. Akutagawa, R. [On-line]. Dostupno preko: http://www.aozora.gr.jp/ cards/000879/files/60_15129.html [28.09.2014.]

Mikan. Akutagawa, R. [On-line]. Dostupno preko: http://www.aozora.gr.jp/ cards/000879/files/98_15272.html [28.09.2017.]

Murakami, H. (1988a). Dansu Dansu Dansu I. Tokio: Koudansha, 2001 (1. izd. 1988).

Murakami, H. (1988b). Dansu Dansu Dansu II. Tokio: Koudansha, 2001 (1. izd. 1988).

Murakami, H. (2001). Supuutonikuno koibito. Tokio: Koudansha.

Murakami, H. (2004). Sputnik ljubav. Beograd: Geopoetika.

Murakami, H. (2013). Igraj igraj igraj (3. izd.). Beograd: Geopoetika.

Ogai, M. (2013). Takasebune. U: Srpski književni list, br. 3/108, 2013

Shiro. Akutagawa, R. [On-line]. Dostupno preko: http://www.aozora.gr.jp/ cards/000879/files/149_15204.html [24.07.2014.]

Soseki, N. (1965). Kokoro. Nihonno bungaku 13. Tokio: Chukoronsha.

Soseki. N. (2003). Duša. Sombor: Publikum.

Tabako to akuma. Akutagawa, R. [On-line]. Dostupno preko: http://www. aozora.gr.jp/cards/000879/files/163_15142.html [28.09.2017.]

Takasebune. Ogai, M. [On-line]. Dostupno preko: http://www.aozora. gr.jp/cards/000129/files/45245 22007.html [24.07.2014.]

Yabu no naka. Akutagawa, R. [On-line]. Dostupno preko: http://www. aozora.gr.jp/cards/ 000879/files/179_15255.html [28.09.2017.] 
Divna Glumac

\section{Summary}

\section{MEANING OF JAPANESE CAUSATIVE AND SOME PROBLEMS IN ITS TRANSLATION INTO THE SERBIAN}

Japanese causative sentences, contrasted to Serbian, show specific distinctions. In Japanese, the meaning of causative is clearly established in the morphological structure, while in Serbian it is formalized on the lexical and syntactic level. In Japanese causative sentence, the act of a causer is included in the apstract auxiliary verb saseru and is not explicitely defined, while in Serbian, the nature of stimulus must be expressed by a concrete causative verb, such as narediti (to order) ili dozvoliti (to permit), which makes the main difference between the two languages. Besides, Japanese causative sentences describe the meanings and relationships which are not included by the concept of causativity in Serbian. Through the analysis of the translation, this research aims to discover systematic relationships that allow the establishment of equivalence in translation of Japanese causative sentences in Serbian, despite the differences. The corpus consists of modern literary works in Japanese written from the early $20^{\text {th }}$ century to the present day and of their translations into Serbian.

Key words: causative, causative verbs, modality, sentence perspective, cause 